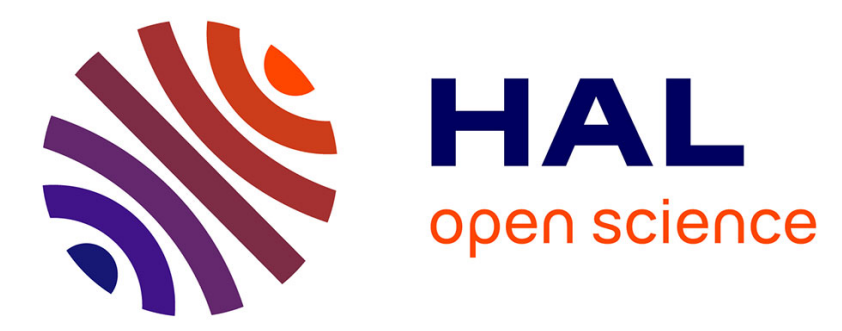

\title{
A Photonic Transmitter for Beam Switching in mm-wave Wireless Links
}

\author{
A.J. Pascual, T. Batte, O. de Sagazan, G. Carpintero, R. Sauleau, D. \\ Gonzalez-Ovejero
}

\section{- To cite this version:}

A.J. Pascual, T. Batte, O. de Sagazan, G. Carpintero, R. Sauleau, et al.. A Photonic Transmitter for Beam Switching in mm-wave Wireless Links. 45th International Conference on Infrared, Millimeter, and Terahertz Waves, IRMMW-THz 2020, Nov 2020, Buffalo (virtual), United States. pp.9370475, 10.1109/IRMMW-THz46771.2020.9370475 . hal-03248654

\section{HAL Id: hal-03248654 https://hal.science/hal-03248654}

Submitted on 4 Jun 2021

HAL is a multi-disciplinary open access archive for the deposit and dissemination of scientific research documents, whether they are published or not. The documents may come from teaching and research institutions in France or abroad, or from public or private research centers.
L'archive ouverte pluridisciplinaire HAL, est destinée au dépôt et à la diffusion de documents scientifiques de niveau recherche, publiés ou non, émanant des établissements d'enseignement et de recherche français ou étrangers, des laboratoires publics ou privés. 


\title{
A photonic transmitter for beam switching in mm-wave wireless links
}

\author{
A. J. Pascual ${ }^{1}$, T. Batté ${ }^{2}$, O. de Sagazan ${ }^{1}$, G. Carpintero ${ }^{3}$, R. Sauleau ${ }^{1}$, and D. González-Ovejero ${ }^{1}$ \\ ${ }^{1}$ Univ Rennes, CNRS, IETR (Institut d'Electronique et de Télécommunications de Rennes) - UMR 6164, F- \\ 35000, Rennes, France \\ ${ }^{2}$ Institut Foton, INSA (Institut National des Sciences Appliquées) - UMR 6082, Rennes, France \\ ${ }^{3}$ Universidad Carlos III de Madrid, Leganés, Spain
}

\begin{abstract}
This abstract describes the first design and assembly of a photonically-excited antenna at E-band for beam switching in millimeter-wave wireless links. The designed antenna consists of two arrays of stacked patches, with one photodiode feeding each array. The stacked patch provides an impedance bandwidth larger than $23 \%$ and a stable radiation pattern over the E-band. The array is combined with a lens to increase the overall gain. Excitation of either patch array allows beam steering between $\pm 2.7^{\circ}$ for accurate beam alignment.
\end{abstract}

\section{INTRODUCTION}

$I$ NTENSE research efforts carried out over the last decades have put the photonic generation of millimeter $(\mathrm{mm})$ and sub-mm wave radiation in the spotlight. Specifically, the seamless integration of photonic transmitters $(T x)$ with fiber optics, has led to numerous point-to-point wireless links demonstrations [1]. These links require stringent beam alignment control over approximately $\pm 5^{\circ}$ [2]. Antennas with fine beam steering could not only help to alleviate this limitation but also help to enlarge the range of applications for photonic $T x$ (reconfigurable links, imaging, etc.) However, only a few demonstrations of photonic beam steering may be found in the open literature [3]. In these cases, phased arrays are used to steer the beam, but the integration of many active elements, necessary to obtain values of gain ( $>25 \mathrm{dBi}$ ), can be challenging.

The E-band (71-76 GHz and 81-86 GHz) features promising characteristics to cope with the race to data rates in future wireless communications. Notably, it is located within an atmospheric transmission window; it offers an available bandwidth of $2 \times 5 \mathrm{GHz}$; it is less susceptible to adverse meteorological conditions than optical wavelengths, and it presents lower free space loss than higher mm-wave frequencies. In this abstract, we propose a photonic $T x$ for beam switching at E-band to overcome the problem above.

\section{ANTENNA DESIGN AND ASSEMBLY}

The antenna consists of two independent arrays (Fig. 1). Each array is integrated with a photodiode (PD) [4] and is composed of four stacked patches. The bottom patches and the PD polarization network are printed on a $127 \mu \mathrm{m}$-thick Duroid 5880 substrate, whereas the top patches are printed on a quartz superstrate. A $306 \mu \mathrm{m}$-thick micromachined silicon spacer controls the vertical spacing, and alignment marks printed on each layer enable an accurate superstrate positioning (better than $\pm 20 \mu \mathrm{m})$. An impedance bandwidth between 70.1 and 87.7 $\mathrm{GHz}$ is obtained for the array $\left(S_{11}<-10 \mathrm{~dB}\right)$.

\section{RESULTS}

Fig. 2 shows the schematic and ANSYS HFSS simulations of beam switching using the proposed antenna. It is placed at
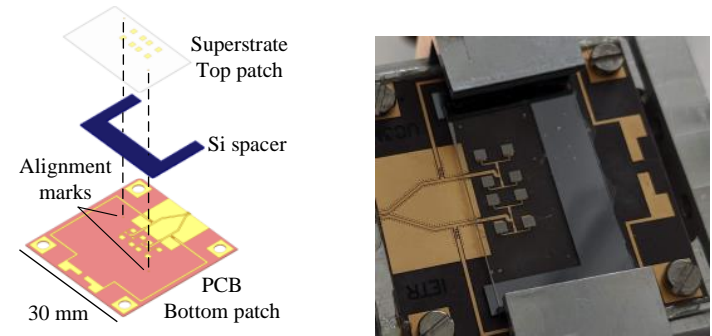

Fig. 1. Left: Stack of antenna layers with the bottom patches printed on the PCB and the top ones printed on a quartz superstrate. Right: assembled prototype.
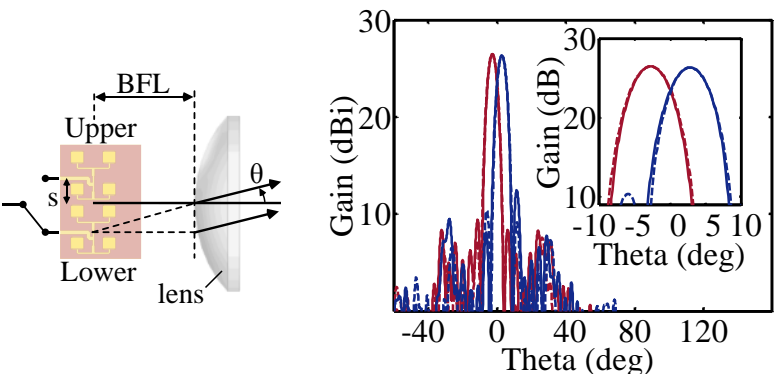

Fig. 2. Left: A $2 \times 1$ array of patches at the focal plane of a lens. Right: Simulated gain for the upper (red) and lower (blue) arrays. Continuous line: along the plane of the drawing. Dashed line: perpendicular to the plane to the drawing.

the back focal length ( $b f l)$ of a PTFE lens $(b f l=53 \mathrm{~mm}, \Phi=5$ $\mathrm{cm})$ so that the two arrays lie symmetrically out-of-axis a distance $s$. The excitation of either independent array generates a tilted beam at $\theta \approx \pm s / b f l$. The tilt is controlled by their spacing or lens focal length. We achieve beam switching between $\pm 2.7^{\circ}$, with crossing at $-3 \mathrm{~dB}$, and a stable pointing direction across the E-band. Note the antenna can be scaled in 1-D for an increased scanning range.

\section{SUMMARY}

This abstract proposes a broadband solution for beam switching by a photonic $T x$ at E-band. This feature is advantageous for beam alignment in several applications employing photonic $T x$ at $\mathrm{mm}$ or sub-mm wave frequencies. A prototype has been designed and assembled. Measurements of the radiation pattern and performance in a wireless link will be available by the time of the conference.

\section{REFERENCES}

[1]. T. Nagatsuma, and G. Carpintero, "Recent progress and future prospect of photonics-enabled terahertz communications," IEICE Trans. Electron., vol. E98-C, pp. 1060-1070, Dec., 2015.

[2]. J. Ala-Laurinaho et al., "2-D beam-steerable integrated lens antenna system for 5G E-band access and backhaul," IEE Trans. Microw. Theory Tech., vol. 64, pp. 2244-2255, Jul., 2016.

[3]. S. Preu et al., "Fiber-coupled 2-D n-i-pn-i-p superlattice photomixer array," IEEE Trans. Antenn. Propag., vol. 65, pp. 3474-3480, Jul., 2017.

[4] A. J. Pascual et al., "A scalable photomixing array for increased emitter power," Proc. 2019 44 th Int. Conf. Infrared, Millimeter, and Terahertz Waves (IRMMW-THz), pp. 1-2, Paris, France, Sep. 1-6, 2019. 